\title{
Chronic diseases among older people in Amirkola, northern Islamic Republic of Iran
}

S.R. Hosseini, ${ }^{1}$ R.G. Cumming, ${ }^{2}$ P. Sajjadi ${ }^{3}$ and A. Bijani ${ }^{3}$

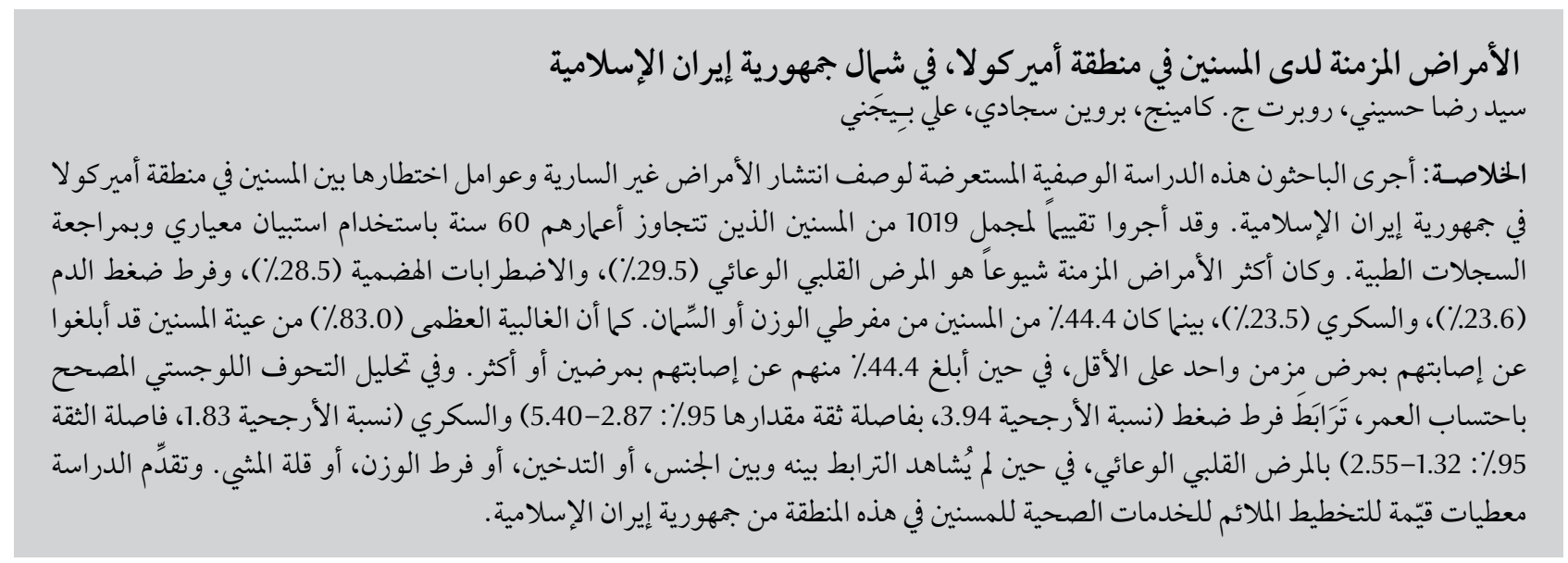

ABSTRACT This descriptive cross-sectional study was undertaken to describe the prevalence of noncommunicable diseases and their risk factors in elderly people in Amirkola, Islamic Republic of Iran. A total of 1019 people aged $60+$ years were assessed using a standard questionnaire and a review of medical records. The most common chronic diseases were cardiovascular disease (29.5\%), digestive disorders (28.5\%), hypertension (23.6\%) and diabetes mellitus $(23.5 \%)$, while $44.4 \%$ of subjects were overweight or obese. Overall, $83.0 \%$ of the sample reported at least 1 chronic disease and $64 \%$ had 2 or more diseases. In age-adjusted logistic regression analysis, hypertension (OR 3.94, 95\% Cl: 2.87-5.40) and diabetes mellitus (OR 1.83, 95\% Cl: 1.32-2.55) were associated with cardiovascular disease, but sex, smoking, overweight and lack of walking were not. The study provides valuable data for planning appropriate health services for elderly people in this area of the Islamic Republic of Iran.

\section{Affections chroniques chez les personnes âgées à Amirkola (Nord de la République islamique d'Iran)}

RÉSUMÉ La présente étude descriptive et transversale a été réalisée pour évaluer la prévalence des maladies non transmissibles et leurs facteurs de risque chez les personnes âgées à Amirkola (République islamique d'Iran). Le dossier médical de 1019 personnes au total, âgées d'au moins soixante ans, et leurs réponses à un questionnaire standard ont été examinés. Les affections chroniques les plus fréquentes étaient les maladies cardio-vasculaires $(29,5 \%)$, les troubles digestifs $(28,5 \%)$, I'hypertension $(23,6 \%$ ) et le diabète $(23,5 \%)$, alors que $44,4 \%$ des sujets étaient en surpoids ou obèses. Globalement, $83,0 \%$ des participants étaient atteints d'une affection chronique et $44,4 \%$ d'au moins deux affections. Selon l'analyse de régression logistique ajustée pour I'âge, l'hypertension (OR : 3,94; IC à $95 \%: 2,87-5,40$ ) et le diabète (OR : 1,83; IC à $95 \%: 1,32-2,55$ ) étaient associés aux maladies cardio-vasculaires, contrairement au sexe, au statut tabagique, au surpoids et à l'absence de pratique de la marche. La présente étude fournit des données précieuses pour la planification de services de santé adéquats destinés aux personnes âgées dans cette zone de la République islamique d'Iran.

'Department of Community Medicine, Social Medicine Research Centre, Babol University of Medical Sciences, Babol, Islamic Republic of Iran (Correspondence to S.R. Hosseini: hosseinim46@yahoo.com).

${ }^{2}$ Department of Epidemiology and Geriatric Medicine, Centre for Education and Research on Ageing, Concord Hospital, University of Sydney, New South Wales, Australia.

${ }^{3}$ Department of Community Medicine, Babol University of Medical Sciences, Babol, Islamic Republic of Iran.

Received: 13/12/09; accepted: 25/02/10 


\section{Introduction}

With declining fertility and increasing life expectancy, the world's population is ageing at an unprecedented rate [1]. The population aged 80 years and older is estimated to increase by $233 \%$ between 2008 and 2040 and the population aged 65 years and over will increase by $160 \%$, compared with an overall population increase across all age groups of only 33\% [2]. Ageing is now a challenge that affects developed and developing countries throughout the world. In the Islamic Republic of Iran, the proportion of elderly people is increasing due to a decreasing birth rate and access to better health care. The proportion of the population aged 60 years and older in 2005 was approximately $7.3 \%$ [3] and is projected to rise to $11.6 \%$ in 2025 and $30.8 \%$ by 2050 [4]. In parallel with this, the frequency of noncommunicable diseases such as diabetes mellitus, coronary heart disease, cancer, pulmonary diseases, cerebrovascular diseases and osteoporosis are rising worldwide [5]. Risk factors such as smoking, high blood pressure, cholesterol, obesity, physical inactivity and unhealthy diet are common to many of these chronic diseases. Primary prevention of even a few of these factors can lead to a reduction in health care expenditures [5].

Despite progress in their diagnosis and treatment, chronic diseases necessitate a long period of care and rehabilitation [6]. Therefore up-todate data about chronic diseases and their risk factors are needed to plan health services for elderly people. To our knowledge, there is little or no published information on the prevalence of noncommunicable diseases in older people in the Islamic Republic of Iran. This lack of information inhibits accurate predictions of the future health care needs of this age group. The aims of this study were to describe the prevalence of noncommunicable diseases and related risk factors among elderly people in an area of northern Islamic Republic of Iran.

\section{Methods}

\section{Sample}

This descriptive cross-sectional community-based study was done in Amirkola, a small town in the north Islamic Republic of Iran that has a population of 25000 , with around 2000 people aged above 60 years. By considering $\alpha=0.05$, $P=0.35-0.40$ and the formula: $N=Z^{2}$ $\times P(1-P) / d^{2}$, the sample size was calculated as $N=971-1024$. The required sample size was based on an estimated prevalence of cardiovascular disease of $35 \%$, with a $95 \%$ confidence interval (CI) of $30 \%-40 \%[7,8]$. All elderly people living in Amirkola are registered with one of 2 health care centres. Participants were randomly selected from the health centre contact lists.

\section{Data collection}

The selected people were visited at their house and were interviewed using a face-to-face standardized questionnaire [9], which took about 1 hour to deliver. All of the elderly people were known to the local health care workers, so the participation rate was $100 \%$. The data collected included sociodemographic characteristics, noncommunicable diseases and their risk factors and type of health insurance. The study interviewers were final year medical students, who informed participants about the details of the study and then completed the study questionnaires by interview with the elderly people or with an informant.

The presence of noncommunicable diseases was determined by asking the question "Have you suffered from any of these health problems (based on physician diagnosis)?" The possible health problems were: cardiovascular diseases, digestive disorders, hypertension, type 2 diabetes mellitus, arthritis, kidney and urinary tract diseases, fractures, ear problems (hearing loss), eye problems (cataract, glaucoma), lung diseases, stroke, cancer, liver and gallbladder disorders, thyroid disorders, migraine headache, depression, epilepsy and convulsions, breast problems and bladder control problems. If a subject reported a health problem, the subject's medical records were reviewed. Selfreported conditions not confirmed by medical record review were considered negative.

Smoking status was determined by asking the question "Are you a smoker and, if so, how many per day?"

Weight was measured using a balance (Beurer $\mathrm{GmbH}$ ) with a minimum of clothes to the nearest $100 \mathrm{~g}$, and height was measured using a stretchless tape metre (an anthropometric rod) to a minimum of $0.5 \mathrm{~cm}$. Body mass index (BMI) was calculated as weight in kilograms divided by the square of height in metres. BMI $\geq 30 \mathrm{~kg} / \mathrm{m}^{2}$ was considered as obese, $25 \leq \mathrm{BMI} \leq 29.9$ $\mathrm{kg} / \mathrm{m}^{2}$ as overweight, $18.5 \leq \mathrm{BMI} \leq 24.9$ $\mathrm{kg} / \mathrm{m}^{2}$ as normal weight and BMI $<18.5$ $\mathrm{kg} / \mathrm{m}^{2}$ as underweight, based on World Health Organization criteria [10].

Data about health insurance was obtained by asking "Are you covered by health insurance?”

\section{Analysis}

The data were analysed using SPSS, version 14 . The statistical tests used in this study were chi-squared test, $t$-test and logistic regression. Logistic regression analysis was performed to assess the relationship between risk factors and presence of noncommunicable diseases; odds ratios (OR) and 95\% $\mathrm{CI}$ are presented. A $P$-value $\leq 0.05$ was considered statistically significant.

\section{Results}

\section{Demographic data}

A total of 1019 people aged 60 years and over were assessed. The mean age was 70 (SD 7) years (range 60-97 years). 


\begin{tabular}{|c|c|c|c|c|c|c|}
\hline \multirow[t]{2}{*}{ Characteristic } & \multicolumn{2}{|c|}{$\begin{array}{c}\text { Male } \\
(n=604)\end{array}$} & \multicolumn{2}{|c|}{$\begin{array}{l}\text { Female } \\
(n=415)\end{array}$} & \multicolumn{2}{|c|}{$\begin{array}{l}\text { Both sexes } \\
(n=1019)\end{array}$} \\
\hline & No. & $\%$ & No. & $\%$ & No. & $\%$ \\
\hline \multicolumn{7}{|l|}{ Age group (years) } \\
\hline $60-64$ & 91 & 15.1 & 75 & 18.1 & 166 & 16.3 \\
\hline $65-74$ & 335 & 55.5 & 234 & 56.4 & 569 & 55.8 \\
\hline $75-84$ & 149 & 24.7 & 83 & 20.0 & 232 & 22.8 \\
\hline$\geq 85$ & 29 & 4.8 & 23 & 5.5 & 52 & 5.1 \\
\hline \multicolumn{7}{|l|}{ Educational status } \\
\hline Illiterate & 359 & 59.5 & 317 & 76.6 & 676 & 66.9 \\
\hline Primary & 152 & 25.2 & 80 & 19.3 & 232 & 23.0 \\
\hline Secondary & 49 & 8.1 & 10 & 2.4 & 59 & 5.8 \\
\hline High school & 31 & 5.1 & 6 & 1.4 & 37 & 3.7 \\
\hline University & 12 & 2 & 1 & 0.2 & 13 & 1.3 \\
\hline \multicolumn{7}{|l|}{ Employment status } \\
\hline Housewife & 4 & 0.7 & 371 & 95.6 & 375 & 37.1 \\
\hline Employed & 376 & 65.1 & 2 & 0.5 & 378 & 37.4 \\
\hline Retired & 198 & 34.3 & 15 & 3.9 & 213 & 21.1 \\
\hline \multicolumn{7}{|l|}{ Marital status } \\
\hline Never married & 0 & 0.0 & 1 & 0.2 & 1 & 0.1 \\
\hline Married & 516 & 85.6 & 284 & 68.4 & 800 & 79.2 \\
\hline Divorced & 3 & 0.5 & 2 & 0.5 & 5 & 0.5 \\
\hline Widowed & 84 & 13.9 & 128 & 30.8 & 212 & 21.0 \\
\hline
\end{tabular}

Most subjects (55.8\%) were between $65-74$ years and $5.1 \%$ were over 85 years old. There were 604 (59.3\%) male subjects and 415 (40.7\%) females (Table 1). Women had generally lower education levels $(P<0.001)$, were more likely to be single (unmarried, widowed, divorced or separated) ( $P$ $<0.001)$ and had higher unemployment levels $(P<0.001)$. One-quarter (25.0\%) of subjects reported having no health insurance.

\section{Chronic diseases}

The most frequent self-reported noncommunicable diseases were cardiovascular disease (29.6\%), digestive disorders (28.5\%), hypertension (23.6\%), type 2 diabetes mellitus (23.5\%), arthritis (22.2\%), kidney and urinary tract diseases (16.6\%), fractures (16.2\%) and lung diseases (12.8\%) (Table 2). The prevalence of stroke was $4.9 \%$ and cancer was $1.7 \%$. Hypertension $(P=0.07)$, diabetes $(P$
$<0.001)$ and psychiatric diseases $(P$ $<0.001)$ were all more frequent in females than males, while lung diseases $(P=0.015)$ were more frequent in males.

Overall, $83.0 \%$ of subjects reported at least 1 diagnosed disease and 64\% reported 2 or more chronic diseases. The mean number of diseases per person was 2.6 (SD 2.2). The mean numbers of diseases in women $[2.7$ (SD 2.3)] was significantly higher than in men $[2.4$ $($ SD 2.1)] $(P<0.001)$.

\section{Cardiovascular risk factors}

The frequencies of reported cardiovascular risk factors were overweight and obesity (42.8\%), smoking (18.5\%), lack of walking (67.0\%), hypertension (23.6\%) and type 2 diabetes mellitus (23.5\%) (Table 3). Hypertension $(P=$ $0.07)$, diabetes $(P<0.001)$, lack of activity $(P<0.001)$ and obesity $(P<0.001)$ were more common in females than males, while smoking was much more common in males (29.0\%) than females $(3.5 \%)(P<0.001)$. Among smokers, the mean number of cigarettes smoked per day was 7.2 (SD 6.4).

In this study, $5.4 \%$ of people were obese, $38.7 \%$ overweight, $55.1 \%$ were normal weight, and $<1 \%$ were underweight (Table 5). There was a statistically significant difference by sex $(P<0.001)$, with the mean BMI in women $\left[25.6(\mathrm{SD} 3.3) \mathrm{kg} / \mathrm{m}^{2}\right]$ being higher than in men $\left[24.5(\mathrm{SD} 2.7) \mathrm{kg} / \mathrm{m}^{2}\right]$.

Overall, $59.2 \%$ of respondents reported 2 or more cardiovascular risk factors (Table 4). The mean number of risk factors in females [1.92 (SD 0.97)] was significantly higher than in males $[1.70($ SD 0.9) $)(P<0.001)$

\section{Multiple logistic regression analysis}

Table 6 shows the distribution of cardiovascular disease risk factors in the 302 elderly people with cardiovascular disease. The results of age-adjusted and 


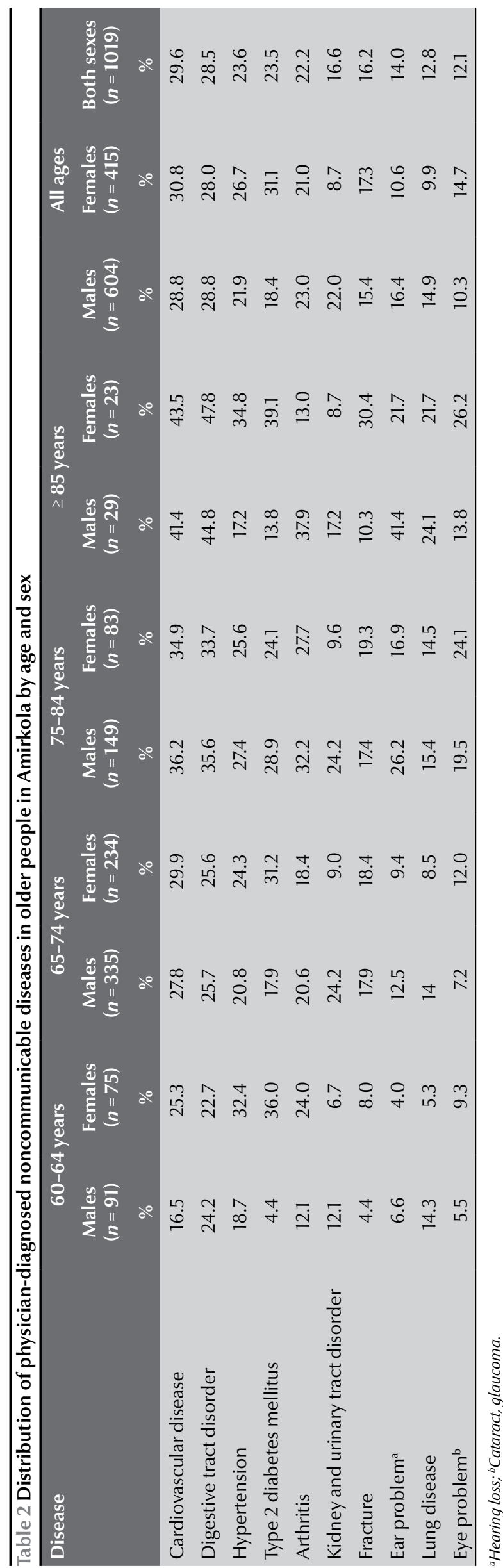

multiple logistic regression models of associations between risk factors and presence of cardiovascular disease (Table 7) showed that hypertension (OR 3.94,95\% CI: 2.87-5.40, $P<$ 0.001 ) and diabetes mellitus (OR 1.83, 95\% CI: 1.32-2.55, $P<0.001)$ were strongly associated with presence of cardiovascular disease, but sex, smoking, overweight and lack of activity were not.

\section{Discussion}

Population ageing is a well recognized phenomenon in developed countries, but developing countries now are ageing much faster than industrialized countries. In 2008 313 million people in the world, $62 \%$ of those aged 60 years and over, lived in developing countries. Reduction in fertility rates, improvements in life expectancy, urbanization, access to better health care and rising income and educational levels have led to this dramatic increase in the ageing population. Noncommunicable diseases are now the major causes of death in the world [2]. As part of the effort to prevent and treat health problems in elderly people, we conducted a study to identify common chronic diseases of elderly people in the town of Amirkola in northern Islamic Republic of Iran.

We found that $83.0 \%$ of people aged 60 years and older in Amirkola had at least 1 diagnosed chronic disease. This is similar to other studies of older people using self-report data, which found that the prevalences of at least 1 chronic disease in Turkey [6], South Korea [11] and India [12] were $80 \%, 78 \%$ and $89 \%$ respectively. In a nationally representative study in the United States, the prevalence of at least 1 chronic disease in people aged 65 years and over was $82 \%$ [13]. In a study in Ireland, based on a pharmacy database, $86 \%$ of those aged 70 years and over had at least 1 chronic disease [14]. In our study in the Islamic Republic of Iran, $64 \%$ of the subjects had at least 2 chronic diseases, a result similar to that found in South Korea (47\%) [11], but lower than in a study in India (83\%) [12]. Caution is needed when comparing the prevalence of chronic diseases between studies because of differences in the age groups studied and sociodemographic characteristics of subjects, differences in the racial and ethnic origins of the study populations and the rates of unreported illnesses. In particular the prevalence of diagnosed disease will depend on the availability and accessibility of health services in an area.

As in other studies [6,11] women had a higher rate of reported morbidity than men in our study. This may be due to elderly women being more likely to be unemployed, widowed and inactive than men; women also tend to be more interested in their health and consequently seek more help for illness than men $[6,11,14]$. 


\begin{tabular}{|c|c|c|c|c|c|c|c|}
\hline \multirow[t]{2}{*}{ Risk factor } & \multicolumn{2}{|c|}{$\begin{array}{c}\text { Males } \\
(n=604)\end{array}$} & \multicolumn{2}{|c|}{$\begin{array}{l}\text { Females } \\
(n=415)\end{array}$} & \multicolumn{2}{|c|}{$\begin{array}{l}\text { Both sexes } \\
(n=1019)\end{array}$} & \multirow[t]{2}{*}{$P$-value } \\
\hline & No. & $\%$ & No. & $\%$ & No. & $\%$ & \\
\hline Hypertension & 131 & 21.7 & 109 & 26.3 & 240 & 23.6 & 0.07 \\
\hline Diabetes mellitus & 111 & 18.4 & 128 & 30.8 & 239 & 23.5 & $<0.001$ \\
\hline Smoking & 174 & 28.8 & 14 & 3.4 & 188 & 18.4 & $<0.001$ \\
\hline Overweight and obesity & 222 & 36.8 & 214 & 51.6 & 436 & 42.8 & $<0.001$ \\
\hline Lack of activity & 376 & 62.3 & 307 & 74.0 & 683 & 67.0 & $<0.001$ \\
\hline
\end{tabular}

In this study the most common chronic disease was cardiovascular disease, found in $29.6 \%$ of the sample. A previous study in the Islamic Republic of Iran found that the prevalence of cardiovascular disease in the northern Gulf region was $14.7 \%$ overall (age range $25-64$ years) and $28.4 \%$ in the oldest age group studied (55-64 years) [15]. In a study in Turkey, the prevalence of reported cardiovascular disease was $28.5 \%$ in people aged 65 years and over [6]. The prevalence of reported hypertension in Amirkola was 23.6\%. This is much lower than in studies of people aged 60 years and over in Turkey
(75.4\%) [16], Taiwan (60.4\%) [17] and India (48\%) [18]. In the United States National Health and Nutrition Examination Survey (NHANES) the prevalence of hypertension was $70.8 \%$ in people aged 65 years and over [19]. The lower prevalence of diagnosed hypertension in Amirkola may be explained by poorer access to health care and the lack of a hypertension screening programme. It could also be due to dietary factors.

The frequency of diagnosed type 2 diabetes mellitus in Amirkola was $23.5 \%$. This is similar to the prevalence of diabetes mellitus in studies

\begin{tabular}{lcc}
\hline $\begin{array}{l}\text { Table } 4 \text { Distribution of number of cardiovascular risk factors present in older } \\
\text { people in Amirkola }\end{array}$ & $\begin{array}{c}\text { No. } \\
(\boldsymbol{n}=\mathbf{9 7 6})^{\mathrm{b}}\end{array}$ \\
\hline No. of risk factors $^{\mathrm{a}}$ & 54 & 5.5 \\
\hline 0 & 344 & 35.2 \\
1 & 377 & 38.6 \\
2 & 159 & 16.3 \\
3 & 40 & 4.1 \\
4 & 2 & 0.2 \\
\hline 5
\end{tabular}

${ }^{a}$ Risk factors were hypertension, diabetes mellitus, cigarette smoking, body mass index $\geq 25 \mathrm{~kg} / \mathrm{m}^{2}$ and lack of walking; ${ }^{b}$ Data were missing for 43 subjects.

\begin{tabular}{lrrrrrr}
\hline \multicolumn{3}{l}{ Table 5 Distribution of body mass index (BMI) in older people in Amirkola } \\
\hline BMl category & \multicolumn{2}{c}{$\begin{array}{c}\text { Males } \\
(\boldsymbol{n}=593)\end{array}$} & \multicolumn{2}{c}{$\begin{array}{c}\text { Females } \\
(\boldsymbol{n}=395)\end{array}$} & \multicolumn{2}{c}{$\begin{array}{c}\text { Both sexes } \\
(\boldsymbol{n}=\mathbf{9 8 8})\end{array}$} \\
& No. & $\%$ & No. & $\%$ & No. & $\%$ \\
Underweight & 4 & 0.7 & 4 & 1.0 & 8 & 0.8 \\
Normal weight & 368 & 62.0 & 177 & 44.8 & 545 & 55.1 \\
Overweight & 200 & 33.7 & 182 & 46.1 & 382 & 38.7 \\
Obese & 21 & 3.5 & 32 & 8.1 & 53 & 5.4 \\
\hline
\end{tabular}

based on self-reports in Turkey (27\%) [16] and South Korea (15\%) [11]. The prevalence of diabetes in the age group 65 years and over was $13.7 \%$ in Australia [20] and 21\% in the United States [19], based on blood glucose measurement. Urbanization, physical inactivity, unhealthy diet and obesity have been implicated in the etiology of diabetes [21].

Cancer was relatively infrequent in this sample of older people in Amirkola, which is possibly attributable to the risk of early death in this age group, leading to low prevalence, rather than low incidence, of cancer.

Overall $18.5 \%$ of participants in our study smoked $(28.8 \%$ of men and $3.4 \%$ of women). The rate of smoking was $28 \%$ in Lebanon [22], 20\% in Turkey [16] and $61 \%$ in men in Korea [23] and $22 \%$ in men and $17 \%$ in women in Canada [24]. Since smoking is an important cause of chronic disease, education of the community about the adverse effects of smoking may help to reduce the occurrence of chronic diseases. Education should target all age groups, including older people.

In our study, $0.8 \%$ of elderly people were underweight and $44.1 \%$ were overweight or obese. This is lower than in the United States, where in the NHANES $70 \%$ of people aged 60 years and over were overweight or obese [25]. In contrast, in a national study in Turkey $49 \%$ of people aged 60-69 years and 38\% of people aged 70 years and over were overweight or obese [26]. 


\begin{tabular}{lccc}
\hline \multicolumn{1}{l}{ Table 6 Presence of cardiovascular disease by cardiovascular disease risk factor in older people in Amirkola } \\
\hline Risk factor present & Cardiovascular disease present & P-value \\
& Yes $(n=302)$ & No $(\boldsymbol{n}=717)$ & 0.186 \\
Smoking & $\%$ & 19.0 & $<0.001$ \\
Hypertension & 15.6 & 15.4 & $<0.001$ \\
Diabetes mellitus & 44.0 & 19.2 & 0.095 \\
BMI $>25 \mathrm{~kg} / \mathrm{m}^{2}$ & 33.8 & 8.2 & 0.958 \\
Lack of activity & 11.6 & 67.3 & \\
\hline
\end{tabular}

$B M I=$ body mass index

Table 7 Multiple logistic regression analysis of the association between cardiovascular risk factors and cardiovascular disease in older people in Amirkola

\begin{tabular}{|c|c|c|c|c|c|c|}
\hline \multirow[t]{2}{*}{ Risk factor } & \multirow{2}{*}{$\begin{array}{c}\text { Age- } \\
\text { adjusted OR }\end{array}$} & \multirow[t]{2}{*}{$95 \% \mathrm{Cl}$} & \multirow[t]{2}{*}{$P$-value } & \multicolumn{2}{|c|}{ Multiple logistic regressiona } & \multirow[t]{2}{*}{$P$-value } \\
\hline & & & & OR & $95 \% \mathrm{Cl}$ & \\
\hline Age & 1.04 & $1.02-1.06$ & $<0.001$ & 1.04 & $1.02-1.06$ & $<0.001$ \\
\hline Sex & 1.12 & $0.85-1.48$ & 0.41 & 0.96 & $0.69-1.33$ & 0.81 \\
\hline Smoking & 0.84 & $0.58-1.21$ & 0.35 & 0.89 & $0.59-1.33$ & 0.57 \\
\hline Hypertension & 4.39 & $3.22-5.98$ & $<0.001$ & 3.94 & $2.87-5.40$ & $<0.001$ \\
\hline Diabetes mellitus & 2.08 & $1.53-2.83$ & $<0.001$ & 1.83 & $1.32-2.55$ & $<0.001$ \\
\hline $\mathrm{BMI} \geq 25 \mathrm{~kg} / \mathrm{m}^{2}$ & 1.06 & $0.80-1.39$ & 0.68 & 1.04 & $0.76-1.42$ & 0.78 \\
\hline Lack of activity & 0.94 & $0.71-1.26$ & 0.67 & 0.95 & $0.68-1.32$ & 0.76 \\
\hline
\end{tabular}

${ }^{a}$ Combining all variables in the model.

$O R=$ odd ratio; $C I=$ confidence interval; $B M I=$ body mass index.

Our study had several limitations. First, Amirkola is a small town in the northern region and so we are not able to generalize these findings to the national population of the Islamic Republic of Iran. A related issue is that undiagnosed conditions would not have been captured by our data collection method. Finally, in a crosssectional study, the cause and effect relationship between risk factors and disease is difficult to assess. To resolve this problem, we are planning a cohort study of the entire older population of Amirkola.

\section{Conclusion}

This study provides a valuable insight into chronic diseases among older people in this part of northern Islamic Republic of Iran. Given the high prevalence of chronic diseases, especially cardiovascular diseases, a national policy on the health of older people is needed that includes a screening programme for hypertension and diabetes among older people.

\section{Acknowledgements}

The authors would like to thank the Deputy for Research at Babol University of Medical Sciences for financial support given to this project (grant no. 1791811469).We also appreciate the help and support of all staff in health care centres in Amirkola.

\section{References}

1. De Flávia OMM et al. Fatores de risco para mortalidade em idosos [Risk factors for mortality among elderly people]. Revista de Saude Publica, 2006, 40:1-7.

2. Kinsella K, He W. An aging world: 2008. International population reports. Washington DC, United States Government Printing Office, 2009.

3. Publications information base statistical centre of Iran [website] (http://amar.sci.org.ir/, accessed 18 September 2011) [in Farsi].

4. World population prospects. The 2006 revision. New York, United Nations, 2007.
5. Maaten $\mathrm{S}$ et al. Chronic disease risk factors associated with health service use in the elderly. BMC Health Services Research, 2008, 8:237.

6. Sevgi $\mathrm{C}$ et al. The prevalence of chronic diseases and quality of life in elderly people in Samsun. Turkish Journal of Medical Science, 2003, 33:335-340.

7. Bahrami $\mathrm{H}$ et al. Obesity and hypertension in an Iranian cohort study; Iranian women experience higher rates of obesity and hypertension than American women. BMC Public Health, 2006, 6:158. 
8. Hadaegh F et al. Prevalence of coronary heart disease among Tehran adults: Tehran Lipid and Glucose Study. Eastern Mediterranean health journal, 2009, 15:157-166.

9. Risk factor questionnaire. Canadian Study of Health and Aging [website]. (http://csha.ca/r_risk_factor_questionnaire.asp, accessed 24 August 2011).

10. Seidell JC, Flegal KM. Assessing obesity: classification and epidemiology. British Medical Bulletin, 1997, 53:238-252.

11. Woo E- et al. Morbidity and related factors among elderly people in South Korea: results from the Ansan geriatric (AGE) cohort study. BMC Public Health, 2007, 7:10.

12. Joshi K, Kumar R, Avasthi A. Morbidity profile and its relationship with disability and psychological distress among elderly people in Northern India. International Journal of Epidemiology, 2003, 32:978-987.

13. Wolff JL, Starfield B, Anderson G. Prevalence, expenditures, and complications of multiple chronic conditions in the elderly. Archives of Internal Medicine, 2002, 162:2269-2276.

14. Naughton C, Bennett K, Feely J. Prevalence of chronic in disease the elderly based on a national pharmacy claims database. Age and Ageing, 2006, 35:633-636.

15. Nabipour I et al. Unhealthy lifestyles and ischaemic electrocardiographic abnormalities: the Persian Gulf Healthy Heart Study. Eastern Mediterranean Health Journal, 2008, 14:858-868.

16. Ozkara A et al. Population-based cardiovascular risk factors in the elderly in Turkey: a cross-sectional survey. Central European Journal of Medicine, 2008, 3:173-178.

17. Lu F-H et al. Hypertension in elderly persons its prevalence and associated cardiovascular risk factors in Tainan city, southern Taiwan. Journal of Gerontology. Series A, Biological Sciences and Medical Sciences, 2000, 55:M463-468.
18. Prakash R, Choudhary SK, Uday SS. A study of morbidity pattern among geriatric population in an urban area of Udaipur, Rajasthan. Indian Journal of Community Medicine, 2004, 29:35-40.

19. McDonald M et al. Prevalence, awareness, and management of hypertension, dyslipidemia, and diabetes among United States adults aged 65 and older. Journals of Gerontology. Series A, Biological Sciences and Medical Sciences, 2009, 64A:256-263.

20. Health of older people in Australia: a snapshot, 2004-05. Australian Bureau of Statistics [website] (http://www.abs.gov.au, accessed 24 August 2011).

21. Dong $Y$ et al. Prevalence of type 2 diabetes in urban and rural Chinese populations in Qingdao, China. Diabetic Medicine, 2005, 22:1427-1433.

22. Chaaya M, Mehio-Sibai A, El-Chemaly S. Smoking patterns and predictors of smoking cessation in elderly populations in Lebanon. International Journal of Tuberculosis and Lung Disease, 2006, 10:917-923.

23. Ko M, Kim M, Nam J. Assessing risk factors of coronary heart disease and its risk prediction among Korean adults: the 2001 Korea National health and Nutrition Examination Survay. International Journal of Cardiology, 2006, 16:187-190.

24. Langille DB et al. Prevalence of risk factors for cardiovascular disease in Canadians 55 to 74 years of age: results from the Canadian Heart Health Surveys, 1986-1992. Canadian Medical Association Journal, 1999, 161:S3-S9.

25. Ogedn CL et al. Prevalence of overweight and obesity in the United States, 1999-2004. Journal of the American Medical Association, 2006, 295:1549-1555.

26. Delibasi T et al. National prevalence of underweight, overweight and obesity in Turkey: cross sectional study of a representative adult population. Central European Journal of Medicine, 2007, 2(3):294-303. 